\title{
Advances in Precipitation Measurements and Sciences
}

\author{
Dong-Bin Shin ${ }^{1} \cdot$ Ziad Haddad $^{2} \cdot$ Ralph Ferraro ${ }^{3,4,5}$ \\ Published online: 29 May 2020 \\ (C) Korean Meteorological Society and Springer Nature B.V. 2020
}

The International Precipitation Working Group (IPWG) is one of the science groups to improve satellite system utilization within the Coordination Group for Meteorological Satellites (CGMS) sponsored by the World Meteorological Organization (WMO). IPWG is interested in quantitative precipitation measurements from operational and research perspectives. Its endeavor is to foster the development of better precipitation measurements, the improvement of scientific understanding of the related processes, and the development of international partnerships. IPWG organizes the series of workshops every 2-years to exchange recent scientific issues, gather opinions and recommendations on new and ongoing satellite missions for precipitation and specifically advice CGMS.

The 9th workshop of IPWG was held in November 2018 in Yonsei University, Seoul, Korea. The workshop consisted of major topics including new and ongoing satellite programs, retrieval algorithms, validations of various precipitation products, precipitation science in meteorology, hydrology, oceanography, climate, emerging applications such as health, flood and drought monitoring, and risk assessments. The workshop also featured three interactive sessions, during which the attendees were invited to participate in discussing and making plans to address important issues for IPWG. Two interactive sessions dealt with the IPWG-the Global Water and Energy Experiment (GEWEX) Data and Assessment Panel (GDAP) assessment of global precipitation products. One interactive session was devoted to "looming challenges" to the production of global satellite precipitation estimates. Intensive meetings of the working groups on Research, Validation, Data assimilation and scattering, and Applications followed. In parallel to the workshop, a satellite data training event was held. The separate training activity focused on new and emerging satellite technologies, sensors, and precipitation datasets.

The workshop included 69 oral presentations and 47 posters to share precipitation related sciences and applications to the scientific community. As a part of the workshop efforts, the special issue "Advances in Precipitation Measurements and Sciences" is published. We would like to thank all the participants to the 9th workshop of IPWG and for the contributions to this special issue.

Publisher's Note Springer Nature remains neutral with regard to jurisdictional claims in published maps and institutional affiliations.
Dong-Bin Shin

dbshin@yonsei.ac.kr

1 Department of Atmospheric Sciences, Yonsei University, Seoul, South Korea

2 Jet Propulsion Laboratory (JPL), California Institute of Technology, Pasadena, CA, USA

3 Satellite Climate Studies Branch, NOAA/NESDIS/STAR, College Park, MD, USA

4 NOAA/NESDIS, ESSIC/CICS, University of Maryland College Park, College Park, MD 20742, USA 